\title{
Absence of Borrelia burgdorferi in the myocardium of subjects with normal left ventricular systolic function: a study using PCR and electron microscopy
}

\author{
Petr Kuchynka ${ }^{\mathrm{a}, \mathrm{b}}$, Tomas Palecek ${ }^{\mathrm{a}, \mathrm{b}}$, Tomas Grusc, Jaroslav Lindner ${ }^{\mathrm{c}}$, Dagmar Berenova ${ }^{\mathrm{d}}$, \\ Zuzana Kurzovad ${ }^{d}$ Pavla Balatova ${ }^{d}$, Daniel Krsek ${ }^{d}$, Ivana Vitkova ${ }^{e}$, Eduard Nemeceka, \\ Jana Podzimkovaa, Anna Barbara Danek ${ }^{\text {a }}$, Ales Linhart ${ }^{\mathrm{a}}$
}

\begin{abstract}
Background. Several studies have demonstrated the presence of the Borrelia burgdorferi $(B b)$ genome in the myocardium of patients with dilated cardiomyopathy (DCM). To further support a causal relationship between the presence of $B b$ in the heart muscle and the development of DCM, demonstration of the absence of $B b$ in the myocardium of subjects with normal left ventricular (LV) systolic function is needed.

Aim. To determine the prevalence of $B b$ by polymerase chain reaction (PCR) and electron microscopy (EM) in individuals with normal LV systolic function and no history suggestive of myocarditis.

Methods. We investigated 50 patients ( $67 \pm 9$ years, 15 women) with normal LV ejection fraction (EF) $\geq 50 \%$ undergoing cardiac surgery. During surgery, four samples from the right atrial appendage were obtained and subsequently examined by PCR and EM for the presence of $B b$, and by immunohistochemistry to detect inflammatory cells. Serological testing of antibodies against $B b$ was also performed.

Results. Neither PCR nor EM detected $B b$ in any of the subjects. Immunohistological examination revealed myocardial inflammation in 2 individuals (4\%). Serological analysis by enzyme-linked immunosorbent assay demonstrated IgM antibodies against $B b$ in $4 \%$ and $\lg G$ antibodies in $12 \%$ of the study cohort; Western blot revealed lgM as well as $\lg G$ positivity in $14 \%$ of patients.
\end{abstract}

Conclusions. The absence of $B b$ in the myocardium of individuals who undergo cardiac surgery and have normal LV systolic function supports the idea of $B b$ pathogenicity in the development of DCM.

Key words: Borrelia burgdorferi, dilated cardiomyopathy, myocarditis, myocardium

Received: May 2, 2015; Accepted with revision: September 18, 2015; Available online: October 21, 2015

http://dx.doi.org/10.5507/bp.2015.051

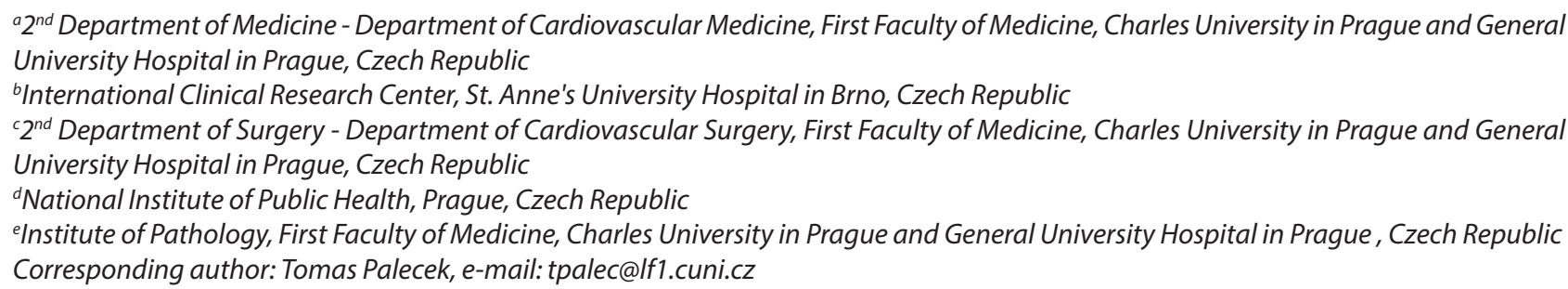

\section{INTRODUCTION}

Dilated cardiomyopathy (DCM) is a term used for dilatation and systolic dysfunction of the left ventricle (LV) $\left(\right.$ ref. $\left.^{1}\right)$. Dilated cardiomypathy may develop as a consequence of acute myocarditis ${ }^{2}$. Myocarditis and DCM are most frequently associated with viral infection of the myocardium ${ }^{3,4}$; however, they may be also triggered by non-viral infectious agents. Within the endemic region of Central Europe there is increasing evidence that Borrelia burgdorferi $(B b)$ may be associated with the development of DCM (ref. $\left.{ }^{5-7}\right)$.

To further support a causal relationship between the presence of $B b$ in the heart muscle and the development of DCM, demonstration of the absence of $B b$ in the myocardium of subjects with normal left ventricular (LV) systolic function is necessary. In this study we aimed to determine the prevalence of $B b$ by polymerase chain reac- tion (PCR) and electron microscopy (EM) in individuals with normal LV systolic function and no history suggestive of myocarditis.

\section{MATERIAL AND METHODS}

The study was prospectively conducted between January 2013 and September 2014. Myocardial samples from 50 adult subjects ( $67 \pm 9$ years; 15 women) with LV ejection fraction $\geq 50 \%$ undergoing myocardial revascularization and/or heart valve surgery were examined. None of the subjects had a previous history of myocarditis or a recent febrile illness, and all had normal plasma levels of CRP and white blood cells. During surgery four samples of right atrial appendage tissue were obtained. Two tissue samples were subsequently examined by PCR and EM for the presence of $B b$, and two samples were examined 
by immunohistochemistry for inflammatory cells. Blood samples obtained from each subject were analyzed serologically for the presence of antibodies against $B b$.

The study design was approved by the local ethics committee and informed written consent was obtained from all subjects prior to participating in this study. The investigation conforms to the principles outlined in the current Declaration of Helsinki.

\section{Laboratory analysis}

Four myocardial samples of right atrial appendage were taken from each study subject.

The first tissue sample was immediately placed in physiologic saline and transported to a dedicated electron microscopy laboratory where it was evaluated for the presence of $B b$. The sample of cardiac tissue $\left(1-2 \mathrm{~mm}^{3}\right)$ was frozen and thawed three times. Subsequently, it was dissected in distilled water $(2 \mathrm{~mL})$ and stored for $20 \mathrm{~min}$ to lyse at room temperature. Thereafter, low speed centrifugation ( $665 \mathrm{~g}$ for $5 \mathrm{~min}$ ) of the samples was performed to remove cell debris. The supernatants were centrifuged ( $11180 \mathrm{~g}$ for $60 \mathrm{~min}$ at $4^{\circ} \mathrm{C}$ ) and sediments were re-suspended in a small amount of distilled water. Suspensions were applied onto 2400-mesh copper grids coated with $1 \%$ polyvinyl formal (Formvar) and reinforced with a carbon layer. Two grids were used for each suspension; one was negatively stained with $2 \%$ ammonium molybdate and the other was stained with $2 \%$ aqueous uranyl acetate. Since aqueous uranyl acetate and ammonium molybdate have different staining properties, both stains were applied in parallel to all samples. Both grids were examined for $B b$ under a JEOL JEM-100 CX II electron microscope at a magnification of 30000x. The sensitivity of trasmission electron microscopy depends on the concentration of $B b$ particles in the examined tissue sample. The detection limit is usually $10^{6} / \mathrm{mL}$ if no concentration method is used and can be decreased to $5 \times 10^{4} / \mathrm{mL}$ if concentration method is applied ${ }^{8}$.

The second myocardial sample was immediately placed in physiological saline and transported to a dedicated laboratory where it was analysed by PCR for the presence of the $B b$ genome. A DNeasy Blood \& Tissue Kit (Qiagen ${ }^{\circledR} \mathrm{GmbH}$, Hilden, Germany) was used for purification of total DNA from the myocardial tissue samples. Starting from $\sim 25 \mathrm{mg}$ of tissue, the protocol was followed for purification of total DNA from tissue according to the manufacturer's instructions. DNA was eluted in a final volume of $200 \mu \mathrm{L}$ of AE buffer. Nested PCR using ospA primers (coding for the outer surface protein A) (ref. ${ }^{9}$ ) and a real time PCR targeting 16S rRNA gene (GeneProof Borrelia burgdorferi kit, GeneProof, Czech Republic) were performed in parallel. The analytical sensitivity of the GeneProof Borrelia burgdorferi kit is 0.572 copies/ $\mu \mathrm{L}(P=0.05)$. This kit detects Borrelia burgdorferi sensu lato species (B. burgdorferi sensu stricto, B. garinii, B. afzelii, B. andersonii, B. bissettii, $B$. valaisiana, B. lusitaniae, B. japonica, B. tanukii, B. turdi, B. sinica) and it doesn't detect human DNA nor DNA of other related or unrelated pathogens. For the purpose of specificity verification and sequencing of possible positive samples, we used nested PCR targeting the OspA gene ${ }^{9}$. We included a positive control of genomic DNA of Borrelia garinii strain 192M ( ref. $^{10}$ ), a negative control of amplification $\left(\mathrm{H}_{2} \mathrm{O}\right)$, and a negative control of isolation (no sample) in each run.

The remaining two samples of myocardial tissue were placed in $10 \%$ formalin solution and transported to a dedicated pathological laboratory where they were subjected to immunohistochemical analysis. Immunohistochemical analysis comprised of staining for leukocyte common antigen-positive cells (LCA+), CD3+ (T-lymphocytes) and CD68+ (macrophages) immunocompetent cells, as well as for HLA-DR positivity. Myocardial inflammation was defined as the presence of $\geq 14$ leucocytes $/ \mathrm{mm}^{2}$ including $\geq 7$ lymphocytes $/ \mathrm{mm}^{2}$ (ref. ${ }^{11}$ ). The enhanced expression of HLA DR (class 2 or 3 ) was supportive for a diagnosis of myocardial inflammation ${ }^{11}$.

Serological testing of $\operatorname{IgM}$ and $\operatorname{IgG}$ antibodies against $B b$ was based on an enzyme-linked immunosorbent assay test (ELISA, Vidia, Prague, Czech Republic) with subsequent confirmation by Western blot testing (WB, Test Line, Brno, Czech Republic).

\section{Statistical Analysis}

Data were expressed as means \pm standard deviation or as a number and percentage of subjects, as appropriate. Statistical analysis was performed with JMP 5.1 statistical software (SAS Institute Inc., Cary, NC, USA).

\section{RESULTS}

The majority of study subjects (33 individuals, 66\%) underwent only surgical myocardial revascularization. Isolated heart valve surgery was performed in 12 (24\%) subjects and a combined surgical procedure (coronary artery bypass grafting together with heart valve surgery) was performed in $5(10 \%)$ patients.

Using PCR and electron microscopy, no $B b$ was found in the myocardium of any of the study subjects. Immunohistochemical signs of myocardial inflammation were detected in 2 (4\%) individuals (Fig.1). Enhanced HLA-DR expression was detected in just 1 of these 2 patients.

Serological analysis by ELISA demonstrated IgM antibodies against $B b$ in 2 subjects (4\%) and $\mathrm{IgG}$ antibodies in 6 individuals $(12 \%)$; WB revealed $\mathrm{IgM}$ as well as $\mathrm{IgG}$ positivity in 7 patients (14\%). WB confirmed positive results gained by ELISA analysis in all subjects and found an additional 5 subjects with $\operatorname{IgM}$ antibodies positivity and 1 individual with IgG antibodies positivity.

\section{DISCUSSION}

The development of DCM is a frequently reported sequel to viral myocarditis. However, nonviral infectious agents are also involved in DCM pathogenesis. There is limited but increasing evidence that $B b$ infection can be associated with the development of DCM. Borrelia 
burgdorferi was first cultured from the myocardium of a 54-year-old man with long-standing DCM in 1990 $\left(\right.$ ref. $\left.^{12}\right)$. On the other hand, other authors investigating myocardial samples obtained from patients with endstage DCM using PCR were unable to detect $B b$ in any of these subjects ${ }^{13,14}$. Moreover, in endomycardial samples (EMB) from patients with suspected inflammatory heart disease (including individuals with $\mathrm{DCM}$ ) and $B b$ positive serology, the $B b$ genome was not revealed by PCR in any subject ${ }^{15}$.

However, in regions highly endemic for Lyme disease such as the Czech Republic, $B b$ has been repeatedly detected in the myocardium of patients with recent-onset unexplained DCM. In a pilot study from our centre, we have reported a $21 \%$ prevalence of $B b$ in EMB specimens obtained from 39 patients with recent-onset DCM (ref. ${ }^{5}$ ). Similar findings were subsequently published by other Czech authors ${ }^{6}$. Furthermore, in our very recently published study, the $B b$ genome was detected in $22(20 \%)$ out of 110 patients with recent-onset unexplained DCM $\left(\right.$ ref. $\left.^{7}\right)$. All $B b$-positive patients were treated with intravenous ceftriaxone for 21 days in addition to conventional heart failure medication and showed significant improvement of LV ejection fraction and heart failure symptoms at one-year follow-up.

In the present study, $B b$ was not detected in the myocardial samples of any subject undergoing cardiac surgery with preserved LV systolic function, using PCR and EM. The absence of $B b$ in these individuals further supports a causal relationship between the presence of $B b$ in the heart muscle and the development of DCM.

Serological tests for antibodies to $\mathrm{Bb}$ have been the mainstay of laboratory diagnosis of Lyme disease ${ }^{16}$. However, Lyme borreliosis is primarily a clinical diagnosis and serological analysis is thus rather supportive in the diagnostic process ${ }^{17}$. In our study, ELISA detected IgM antibodies against $B b$ in 2 subjects and $\mathrm{IgG}$ antibodies in 6 individuals, while WB revealed IgM as well as IgG positivity in 7 patients. None of these patients had a history of Lyme disease or clinical signs suspicious of Lyme disease. It is well known that decreased specificity leading to false positivity of these serological assays could be caused by factors directly linked with the assays, such as the use of too low cut-off levels or the presence of cross-reacting antibodies ${ }^{18}$. Other factors may influence these serological methods indirectly, such as oligoclonal stimulation seen in some viral as well as non-viral infections. Moreover, in regions that are highly endemic for Lyme disease like the Czech Republic, high sero-prevalence of specific antibodies is present in the general population and the relevance to clinical disease is therefore questionable. In recent study by Kodym et al. (ref. ${ }^{19}$ ) sera of 100 healthy blood donors with negative history of Lyme disease were examined and serological examination revealed seropositivity in $29 \%$ of individuals. In more detail, isolated $\operatorname{IgM}$ antibodies against $B b$ were detected in 7\% of the subjects and $\mathrm{IgG}$ antibodies in $17 \%$ of the healthy volunteers. Both IgM and IgG antibodies were positive in $5 \%$ of the blood donors. Based on our findings and results from other stud-

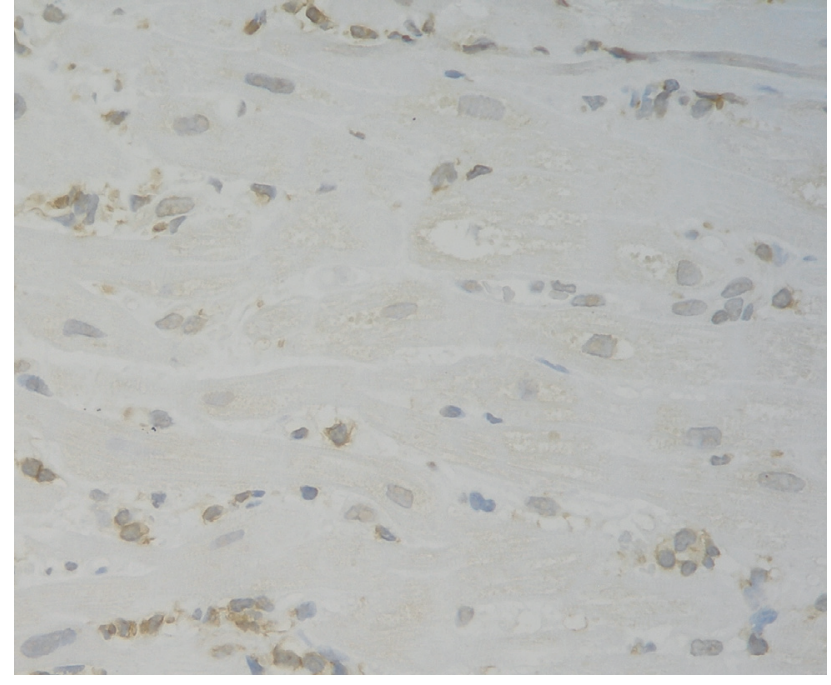

Fig. 1. Myocardial tissue sample depicting presence of CD3 positive T-lymhocytes (CD3 positive cells are stained brown; magnification 200x).

ies we think that isolated positivity of $B b$ antibodies in subjects with no clinical history and signs of Lyme disease is of limited clinical value. Finally, in our subjects with preserved LV systolic function undergoing cardiac surgery immunohistochemical signs of myocardial inflammation were extremely rare. Two subjects met the current criteria for myocardial inflammation ${ }^{20}$ but only one of these two individuals exhibited noncellular HLA-DR positivity, supporting the diagnosis of myocardial inflammation. These findings reiterate those seen in published studies and confirm the utility of the immunohistochemical criteria in the diagnosis of inflammatory DCM (ref. ${ }^{11,21}$ ).

\section{CONCLUSIONS}

The absence of $B b$, as assessed by both PCR and EM, in the myocardium of subjects with normal LV systolic function and no history suggestive of myocarditis, supports the theory of causal relationship between $B b$ infection and DCM development.

Acknowledgement: The project was supported by PRVOUK-P 35/LF1/5, Project reg. no. CZ.2.16/ 3.1.00/24012 from OP Prague Competitiveness, European Regional Development Fund - Project FNUSA-ICRC (No. CZ.1.05/1.1.00/02.0123) and by The Young Researchers Grant of the Czech Society of Cardiology.

Author contribution: PK, TP, TG, AL: study concept and design; PK, TP, TG, DB, ZK, PB, DK, IV, EN, JP, BAD: acquisition of data; PK, TP, DB, ZK, PB, DK, IV, AL: analysis and interpretation of data; PK, TP, JL, EN, JP, BAD, AL: drafting of the manuscript; PK, TP, JL, AL: critical revision of the manuscript.

Conflicts of interest: The authors declare there are no conflicts of interest regarding the publication of this article. 


\section{REFERENCES}

1. Elliott $P$, Andersson $B$, Arbustini $E$, Bilinska $Z$, Cecchi $F$, Charron $P$ Dubourg O, KühI U, Maisch B, McKenna WJ, Monserrat L, Pankuweit S, Rapezzi C, Seferovic P, Tavazzi L, Keren A. Classification of the cardiomyopathies: a position statement from the European society of cardiology working group on myocardial and pericardial diseases. Eur Heart J 2008;29:270-6.

2. Grumbach IM, Heim A, Pring-Akerblom P, Vonhof S, Hein WJ, Müller $\mathrm{G}$, Figulla HR. Adenoviruses and enteroviruses as pathogens in myocarditis and dilated cardiomyopathy. Acta Cardiol 1999;54:83-8.

3. Bowles NE, Ni J, Kearney DL, Pauschinger M, Schultheiss HP McCarthy R, Hare J, Bricker JT, Bowles KR, Towbin JA. Detection of viruses in myocardial tissues by polymerase chain reaction. evidence of adenovirus as a common cause of myocarditis in children and adults. J Am Coll Cardiol 2003;42:466-72.

4. Kühl U, Pauschinger M, Noutsias M, Seeberg B, Bock T, Lassner D Poller W, Kandolf R, Schultheiss HP. High prevalence of viral genomes and multiple viral infections in the myocardium of adults with "idiopathic" left ventricular dysfunction. Circulation 2005;111:887-93.

5. Palecek T, Kuchynka P, Hulinska D, Schramlova J, Hrbackova $H_{\text {, }}$ Vitkova I, Simek S, Horak J, Louch WE, Linhart A. Presence of Borrelia burgdorferi in endomyocardial biopsies in patients with new-onset unexplained dilated cardiomyopathy. Med Microbiol Immunol 2010;199:139-3.

6. Kubánek M, Šramko $M$, Berenová $D$, Hulínská D, Hrbáčková $H$ Malušková J, Lodererová A, Málek I, Kautzner J. Detection of Borrelia burgdorferi sensu lato in edomyocardial biopsy specimens in individuals with recent-onset dilated cardiomyopathy. Eur J Heart Fail 2012;14:588-96.

7. Kuchynka P Palecek T, Havranek S, Vitkova I, Nemecek E, Trckova R, Berenová D', Krsek D, Podzimkova J, Fikrle M, Danek AB, Linhart A. Recent-onset dilated cardiomyopathy associated with Borrelia burgdorferi infection. Herz 2015; DOI: 10.1007/s00059-015-4308-1.

8. Laue M, Bannert N. Detection limit of negative staining electron microscopy for the diagnosis of bioterrorism-related micro-organisms. J Appl Microbiol 2010; 109:1159-68.

9. Moter SE, Hofmann H, Wallich R, Simon MM, Kramer MD. Detection of Borrelia burgdorferi sensu lato in lesional skin of patients with erythema migrans and acrodermatitis chronica atrophicans by ospA-specific PCR. J Clin Microbiol 1994;32:2980-8.

10. Hulínská D, Roubalová K, Schramlová J. Interaction of Borrelia burg dorferi sensu lato with Epstein-Barr virus in lymphoblastoid cells. Folia Biologica 2003;49:40-8.

11. Kühl U, Noutsias M, Seeberg B, Schultheiss HP. Immunohistologica evidence for a chronic inflammatory process in dilated cardiomyopathy. Heart 1996;75:295-300.
12. Stanek G, Klein J, Brittner R, Glogar D. Isolation of Borrelia burgdorferi from a patient with longstanding cardiomyopthy. N Engl J Med 1990;322: 249-252

13. Leeuw N, Melchers WJG, Bals AHMM, Jonge N, Galama JM. Study on microbial persistence in end-stage idiopathic dilated cardiomyopthy. CID 1999;29:522-5.

14. Suedkamp M, Lissel C, Eiffert H, Flesch M, Boehm M, Mehlhorn U, Thomson R,de Vivie ER. Cardiac myocytes of hearts from patients with end-stage dilated cardiomyopathy do not contain Borrelia burgdorferi DNA. AmHeart J 1999;138:269-72.

15. Karatolios K, Maisch B, Pankuweit S. Suspected inflammatory cardiomyopathy: Prevalence of Borrelia burgdorferi in endomyocardial biopsies with positive serological evidence. Herz 2015;40(S1):91-5.

16. Seriburi V, Ndukwe N, Chang Z, Cox ME, Wormser GP. High frequency of false positive lgM immunoblots for Borrelia burgdorferi in clinical practice. Clin Microbiol Infect 2012;18:1236-40.

17. Rebman AW, Crowder LA, Kirkpatrick A, Aucott JN. Characteristics of seroconversion and implications for diagnosis of post-treatment Lyme disease syndrome: acute and convalescent serology among a prospective cohort of early Lyme disease patients. Clin Rheumatol 2015;34:585-9.

18. Magnarelli LA, Miller JN, Anderson JF, Riviere GR. Cross-reactivity of nonspecific treponemal antibody in serologic tests for Lyme disease. J Clin Microbiol 1990;28:1276-9.

19. Kodym $P$, Hořejší J, Kurzová $Z$, Balátová $P$, Berenová $D$, Kracíková J, Jágrová Z, Malý M. Borreliosis in Prague: prevalence in ticks, blood donors and patients of the National Reference Laboratory as compared with reported incidence data. V4 Parasitological Meeting "Parasites in the Heart of Europe“, Stará Lesná, Slovakia, 25.-30.5.2014. ISBN 978-80-968473-7-2 Book of Abstracts:32.

20. Caforio AL, Pankuweit $S$, Arbustini E, Basso C, Gimeno-Blanes J, Felix SB, Fu M, Heliö T, Heymans $S$, Jahns $R$, Klingel $K$, Linhart A Maisch B, McKenna W, Mogensen J, Pinto YM, Ristic A, Schultheiss HP, Seggewiss H, Tavazzi L, Thiene G, Yilmaz A, Charron P, Elliott PM; European Society of Cardiology Working Group on Myocardial and Pericardial Diseases. Current state of knowledge on aetiology, diagnosis, management, and therapy of myocarditis: a position statement of the European Society of Cardiology Working Group on Myocardial and Pericardial Diseases. Eur Heart J 2013;34:2636-48.

21. Krejci J, Hude P, Poloczkova H, Zampachova V, Stepanova R, Freiberger T, Nemcova E, Spinarova L. Correlations of the changes in bioptic findings with echocardiographic, clinical and laboratory parameters in patients with inflammatory cardiomyopathy. Heart Vessels 2014; DOI: 10.1007/s00380-014-0618-0. 